\title{
Pelger-Huet Anomaly
}

National Cancer Institute

\section{Source}

National Cancer Institute. Pelger-Huet Anomaly. NCI Thesaurus. Code C85002.

An autosomal dominant inherited condition caused by mutations in the lamin B receptor gene. It is characterized by defects in the neutrophil lobulation, resulting in the presence of dumbbell-shaped neutrophils with bilobed nuclei in the peripheral blood smear. 